\title{
Mediações étnico-raciais no contexto da educação infantil em Três Lagoas/MS: um estudo de caso
}

Resumo: Objetivamos apresentar/explicitar e tensionar as percepções contextuais na Educação Infantil por meio de um estudo de caso numa instituição escolar Municipal em Três Lagoas/MS. Centramo-nos na prática da professora, que atua com uma turma composta de 27 crianças de $O$ (zero) a 5 (cinco) anos, frente às crianças. Por meio de observações densas no contexto educativo, enquanto instrumento de coleta de dados, empreendemos a metodologia de inspiração etnográfica do estudo de caso de cunho qualitativo para alcançar o nosso objetivo. Tomamos como aporte teórico, tridimensional, os estudos que versam sobre as relações raciais (no Brasil), sociais e culturais no contexto escolar. Os dados indicam uma apaziguadora relação da professora regente no contexto no contexto educativo diante das relações étnico-raciais que sugere uma ausência permanente da intervenção regencial deflagra aquilo que ora denominamos de personalidade racista $(\mathrm{Pr})$ no contexto educacional da pequena infância.

Palavras-chave: Mediações Étnico-raciais; Educação Infantil; Ausência Permanente; Personalidade Racista.

\section{Ethnic-racial mediations in the context of early chil- dhood education in Três Lagoas/MS: a case study}

Abstract: It aims to present/ to clarify and to pressure the contextual perceptions of ethnic-racial issues in the early childhood education through a case study in a Municipal educational institution in Três Lagoas/MS. We focused on the practice of a teacher from preschool. Through in-depth observations in classroom, as instrument for data collection, we inspiration in the ethnographic methodology of the case study in order to achieve our goal, that is, the study configured itself as an ethnographic research with qualitative analysis. A tridimensional study about racial (in Brazil), social and cultural studies in school context, that is, human/subjective relations, provided support for the research. The data collected so far indicate a soothing relation of the teacher on the ethnic-racial relations in the context of the classroom. However, such relation is not extensive to her children, since the permanent absence of her intervention may trigger what we now call racist personality (Rp) in the context of education in the early childhood.

Keywords: Ethnic-racial Mediations; Early Childhood Education; Permanent Absence; Racist Personality.

\footnotetext{
I Este texto é dedicado à Sandra M. Eugenia a quem o processo vivencial não permitiu que visse o seu trabalho divulgado. É com respeito e admiração que compartilho as minhas reflexões com ela.

2 In memoriam.

3 Doutor em Educação pela UFSC/Paris I. Professor Dedicação Exclusiva na UFMS/CPTL. E-mail: christian.mwewa@pq.cnpq.br

4 Doutoranda UFMS/Mackenzie (Dinter). Professora na UFMS/CPTL. E-mail: bispo.silva@bol.com.br
} 


\section{Introdução}

$\mathrm{O}$ artigo que ora apresentamos configura-se como parte de um projeto de pesquisa em andamento (2014-2016). O objetivo geral da referida pesquisa busca explicitar, compreender e analisar, a partir de estudo de caso com inspiração etnográfica, as relações étnico-raciais em uma escola pública de Três Lagoas em Mato Grosso do Sul enquanto estudo piloto. Para o presente recorte, temos como foco principal a professora regente e as relações que esta estabelece com as crianças de uma turma de pré-II, no contexto educativo da Educação Infantil. Assim, a partir de observações, descrevemos como ocorrem as questões étnico-raciais no contexto educativo e como a professora da pré-escola trabalha essas questões.

Para alcançar o objetivo da pesquisa, apoiamo-nos nas observações do contexto educativo enquanto instrumento de coleta de dados a partir da metodologia de inspiração etnográfica empreendemos um estudo de caso ${ }^{1}$. Realizamos as observações em duas fases: a primeira foi desenvolvida entre os meses de Abril e Maio para aproximação/familiarização com o campo; a segunda de Agosto a Novembro de 2014 para realizar as observações propriamente em análise. Em contrapartida fizemos um amplo levantamento bibliográfico no indexador SCIELO, por exemplo, e no Banco de Teses da CAPES. Como embasamento teórico, apropriamo-nos de autores que problematizam e fundamentam as temáticas das relações étnico-raciais na prática pedagógica.

No Brasil, como em outros países lusófonos colonizados por Portugal, a marca da discriminação racial, infelizmente, ainda se faz presente. Em nosso país, foram quase 400 anos de escravidão explícita, cujas sequelas - muitas vezes veladas - ainda se fazem presentes na sociedade na qual se impera uma falsa superioridade branca. Embora tenhamos progredido em termos de Leis que buscam a não segregação relacionada a raça, cor, credo e outros, tais leis não se concretizam por decreto, é na prática, nas ações, no cotidiano que elas se efetivam. Nesse contexto, a educação infantil que exerce um papel social na busca de uma sociedade humanizadora. É na perspectiva de Quinteiro e Carvalho (2012, p. 131) que fincamos a compreensão da infância “[...] como a condição social de ser criança, um sujeito humano de pouca idade, que deve viver esse período de apropriação

\footnotetext{
I Desta forma, buscamos aporte teórico na antropologia que compreende o homem como ser social e cultural. A antropologia utiliza-se principalmente da etnografia, que segundo Clifford Geertz (1978) consiste em um esforço intelectual que vai muito além da aplicação de técnicas que auxiliam na obtenção de dados. Utilizamos nesta pesquisa, a atividade campal para uma visão profunda, ampla e integrada da realidade que se apresenta e o que fica, por vezes, implícito em relação às questões raciais envolvendo a prática pedagógica, para isso o trabalho de observação e registro das aulas, de uma turma de pré-escola, se fez pertinente.
} 
dos elementos da cultura, sendo a educação compreendida como um processo”.

Dessa maneira, é na educação infantil onde as crianças (contexto educativo), ao iniciar as atividades grupais, percebem as diferenças socialmente construídas e instituídas, também, no contexto da educação infantil. Nesse espaço há possibilidade de criar situações favoráveis para as (des) igualdades sociais; para compreender que a miscigenação, existente em nosso país, engendra as diferenças sociais extensivas ao contexto educativo de convívio entre adultos e crianças, principalmente, no contexto educativo. Por ser este um espaço não só de aprendizagens, mas, também, gerador de tensões e conflitos ideológicos, como por exemplo, racismos, preconceitos e discriminações, o que pode motivar a manifestação daquilo que chamamos de Personalidade racista (Pr). Cunhamos o termo personalidade racista (Pr), por entende-lo, no contexto da e na educação da pequena infância como o somatório de preconceito (ignorância do conceito), discriminação (no sentido de segregação) e flagelação (imputação de sacrifícios) infringidos por um agente contextualmente hegemônico $(\mathrm{aH})$ ao sujeito tomado como desviante (sD) ou desviante múltiplo (aquele que agrega diferentes "desvios" socialmente implementados e majoritariamente compartilhados). Ou seja, para que haja a manifestação da Pr é necessário que haja um agente hegemônico diante de um sujeito considerado desviante, portanto $\operatorname{Pr}=\mathrm{aH}+\mathrm{sD}$, impreterivelmente. Em outras palavras, a personalidade racista só se manifesta diante do considerado desviante, em especial, o desviante múltiplo. Termo cunhado para identificar aqueles que estão “[...] propício[s] às ações de terceiros num acúmulo de preconceitos, por exemplo, de gênero, camada social e por atuar numa profissão pouco prestigiada socialmente” (MWEWA e OLIVEIRA, 2013, p. 171).

As crianças, quando vítimas desta personalidade ou quando submetidas às situações de preconceito étnico-racial, por exemplo, impreterivelmente resultam em prejuízos na formação educacional e social. (ROSEMBERG, 1991). As pesquisas da Fúlvia Rosemberg (1981, 1986, 1991, 2014 e 2015) destacam que

Na faixa etária de 0 a 6 anos de idade, encontramos composição racial equivalente ao conjunto da população, bem como padrão equivalente de distribuição pelo território nacional: em 1987, neste grupo etário, 54,4\% das crianças foram declaradas brancas e 45\% pretas e pardas (PNAD, apud Rosemberg, Pinto, 1997). Porém, esta média nacional esconde intensas diferenças regionais. As crianças pretas e pardas superam as brancas, justamente nas regiões economicamente menos desenvolvidas: na zona rural para o conjunto do território nacional; nas regiões Norte, Nordeste e Centro-Oeste. Associando-se densidade populacional e composição racial, observa-se que as crianças brancas residem principalmente no Sudoeste $(70,4 \%)$ e as não-brancas principalmente no Nordeste $(49,8 \%)$. (ROSEMBERG, 1999, p. 25). 
Diante do exposto, o artigo está dividido em quatro partes, quais sejam, (1) essa introdução; (2) o percurso metodológico; (3) Mediações étnico-raciais (existentes no contexto de uma turma de pré-II envolvendo a professora regente e as crianças); a partir do contexto educativo; e (4) algumas considerações.

\section{Na expectativa de uma descrição densa: caminhos metodológi- $\cos$}

Para desenvolver esta pesquisa nos apropriamos da metodologia de estudo de caso com inspiração etnográfica. A equipe que realizou a pesquisa foi composta por um (1) professor orientador; duas (2) pesquisadoras que coletaram os dados ora apresentados; uma (1) professora convidada a criticar e validar as nossas análises. Todos os membros pertencem à Universidade Federal do Mato Grosso do Sul/MS, Campus Três Lagoas/CPTL. Segundo afirma Cerisara et al. (2007, p. 5 grifo dos autores):

[.... o que se coloca como plausibilidade de constituição do campo educativo é, sem dúvida, a criação e o desenvolvimento de pesquisas multidisciplinares, em que a produção do conhecimento possa ser o resultado de diferentes olhares sob um mesmo fenômeno. Neste processo de investigação, cabe à Pedagogia justamente o estudo das relações educativas, seus mecanismos de ação e estruturas subjacentes, inevitavelmente inconclusas e dotadas de um elemento utópico, como característica fundamental do fenômeno educativo.

O estudo tem como locus uma escola do referido município, localizada na periferia da cidade de Três Lagoas no estado de Mato Grosso do Sul/MS. Essa Instituição escolar oferece Educação Infantil para crianças de 4 e 5 anos: Pré-I e Pré-II (crianças de 5 anos antes de completarem 6 anos); Ensino Fundamental que atende do $1^{\circ}$ ao $5^{\circ}$ ano. Assim, como a instituição atende, também, o Ensino Fundamental, nos referimos a ela enquanto escola para demarcar a sua abrangência e enquanto contexto educativo na especificidade da Educação Infantil. Em seus arquivos constam, no ano de 2014, 416 (quatrocentos e dezesseis crianças matriculadas) em idades que variam entre 4 e 12 (quatro e doze) anos e estão distribuídos entre os turnos Matutino e Vespertino. A mesma recebe crianças de famílias das classes populares das zonas urbanas e rural. A comunidade ao redor da escola é composta por famílias de classe média baixa. E, portanto, as crianças e alunos ali matriculados parecem 
pertencer em sua totalidade ao mesmo extrato social. Após fazer algumas indagações à professora, a professora se definiu como pertencente à classe trabalhadora e leciona nessa instituição escolar desde 2007.

A instituição escolar funciona em prédio próprio, as instalações físicas são relativamente adequadas, com sete salas, quadra coberta, sala de informática, refeitório, cozinha, dispensa, pequena horta, dois blocos de banheiro (masculino e feminino), não possui cantina, apenas um espaço pequeno com freezer para venda de sorvetes sendo essa a opção de lanche, além da merenda que é servida todos os dias para as crianças. A biblioteca está sendo construída em prédio anexo e a obra está em fase de conclusão. Para as salas da pré-escola, as carteiras são adequadas à altura das crianças. A área administrativa possui uma sala para direção; antessala para (coordenação), secretaria escolar; sala dos professores; dois banheiros.

Os profissionais da escola, na sua maioria são mulheres, sendo três docentes masculinos, que ministram as disciplinas de artes e educação física. Durante o recreio, as crianças são deixadas "livres" para as atividades de jogos e brincadeiras. No período em que estivemos na escola, percebemos, nessa comunidade escolar, que a sua maioria é composta de negros, de pardos e uma minoria de brancos.

Em relação às atividades que a escola desenvolve, por meio de informações coletadas junto à secretaria, há um leque de datas que são comemoradas junto às crianças, como por exemplo: Páscoa; Tiradentes; descobrimento do Brasil; dia do Trabalho; dia das mães; dia dos pais; dia do livro; do meio ambiente; dia do Índio; dia do professor; dia da consciência negra, dentre outras. A escola também desenvolve vários projetos culturais nos quais há a participação de grande parcela da comunidade escolar. A formação continuada também se faz presente, para isso, a gestão busca efetivar parceria com instituições de Ensino Superior para discutir e problematizar o cotidiano do contexto educativo em busca de uma melhoria na qualidade das relações educativas. Em relação ao material didático, a escola, como as demais da rede municipal de ensino, faz uso de apostilas do Sistema Positivo, que são adquiridas via prefeitura municipal, essa é uma política desenvolvida há anos na cidade. As crianças de pré-escola também recebem o material citado. Outros materiais permanentes e de consumo são adquiridos por meio da Associação de Pais e Mestres e Conselho Gestor, com a verba oriunda do Fundo de Desenvolvimento da Educação e de Valorização dos Profissionais da 
Educação (Fundeb).

A pesquisa se estruturou inicialmente no estudo teórico que nos permitiu um aprofundamento dos conceitos sobre Educação Infantil, relações étnico-raciais no ambiente escolar e afirmação de identidade. Este percurso foi basilar para a efetivação das observações e coleta dos dados da realidade no cotidiano escolar, pois um "olhar atento para escola capta situações que configuram de modo expressivo atitudes racistas" (BRASIL, 2006, p.23).

Nosso olhar se deteve, com maior ênfase, tendo em vista o número de salas e nossa especificidade que é a criança pequena, em uma sala de pré-escola. Optamos pela observação dessa sala porque já tínhamos contato prévio, por conta das atividades do Programa Institucional de Bolsa de Iniciação à Docência (PIBID) realizadas naquele contexto educativo. A escolha da instituição também teve influência do fato de as alunas (pesquisadoras) estarem desenvolvendo nessa instituição o programa PIBID, as quais são bolsistas pelo segundo ano consecutivo. Neste sentido, estabeleceu-se uma relação favorável entre o(as) pesquisador(as) e os sujeitos do estudo o que possibilitou uma melhor captação dos dados. Portanto, a familiaridade com o campo contribuiu de maneira ímpar na qualidade e refinamento dos dados coletados na perspectiva de densificá-las.

Além da observação e registro, mediante inserção no campo de pesquisa, é importante destacar que foram utilizados outros elementos, neste contexto, como por exemplo, duas disciplinas obrigatórias do curso de Licenciatura em Pedagogia da UFMS/CPTL: Pesquisa e Prática Pedagógica (PPP), que tem em sua ementa o caráter de interdisciplinaridade, a articulação como os demais componentes curriculares do curso, de modo que os acadêmicos conheçam a realidade escolar.

As(os) acadêmicas(os), durante a disciplina, tem a oportunidade de vivenciarem os problemas da realidade educacional, refletir sobre eles (os problemas) em diferentes momentos e aulas do curso em trânsito. A pesquisa se efetiva de forma ampla, concreta, profunda. Aliada a essa disciplina de PPP, temos também Tópicos em Igualdade Racial e Diversidade Étnico-racial. Precisamente nessa disciplina são estudados conteúdos relacionados ao racismo. Acreditamos serem fundamentais reflexões teórico-práticas, dessa natureza, num curso que forma professoras/es.

As disciplinas citadas contribuíram para o desenvolvimento do projeto de pesquisa de cunho etnográfico materializado neste artigo que envolve a percepção de adultos e crianças mediante o fenômeno em análise. Para nossas reflexões do espaço educativo, trabalhamos a partir da ideia 
de diversidade cultural, heterogeneidade e diferença (TURA, 1999).

E, portanto, questionar como e se o espaço de convívio entre adultos e crianças reforça a manutenção da estrutura social acaba sendo a pergunta de fundo deste artigo a qual não alcançamos responder, pois não se trata de objetivo imediato e sim futuro em pesquisas com dimensões mais alargadas. Para as contribuições de nossa pesquisa, escolhemos como objeto as relações étnico-raciais que se estabelecem no interior da instituição escolar como norteadoras das nossas observações.

A coleta de dados foi dividida em duas fases por conta da organização semestral do curso ao qual as acadêmicas estão vinculadas: a primeira de Abril e Maio; a segunda de Agosto a Novembro de 2014. Essas fases, por sua vez, foram subdivididas em três etapas, a saber: (1) pesquisa exploratória para caracterização da instituição, verificação dos documentos institucional e conhecer os sujeitos de pesquisa realizada na primeira fase de Abril e Maio. Para realizarmos a pesquisa, fizemos visitas em duas etapas; (2) a elaboração do protocolo de observação a partir das três primeiras observações das/com as crianças, na turma do pré-II antes de definir o objeto. As observações foram realizadas tendo como foco principal a relação adulto (professora)/criança(a) no espaço onde ocorriam as atividades. É pertinente salientar que para a descrição dos fatos utilizamos fichas denominadas de pesquisa exploratória e protocolo de observação; (3) elaboração de um projeto de pesquisa após o levantamento dos dados que orientou a execução da pesquisa e dos resultados, parciais, ora apresentados. Em relação à primeira etapa nos apropriamos, como já anunciado, da metodologia de estudo de caso de inspiração etnográfica e na abordagem qualitativa. Tomamos como conceitos fundantes e orientadores para a análise: pesquisa de inspiração etnográfica, educação Infantil e as relações étnico-raciais. Apesar destes conceitos não estarem explicitados no interior do artigo eles co-habitaram cada etapa de análise dos dados. Esse "acompanhamento" nos auxiliou na elaboração e descrição dos dados apurados na instituição escolar, com foco nas relações da professora com a turma na perspectiva étnico-racial.

[...] a abordagem qualitativa de pesquisa tem suas raízes no final do século XIX quando os cientistas sociais começam a indagar se o método de investigação das ciências físicas e naturais, que por sua vez se fundamentava numa perspectiva positiva como modelo para o estudo dos fenômenos humanos e sociais. (ANDRÉ, 1986, p.16).

Ao indicarem "uma trajetória de pesquisa e indicações para a avaliação de contextos educativos", Cerisara, Rocha e Filho (2007 p. 3).), traçam os percursos trilhados pelas produções acadêmi- 
cas realizadas no âmbito do Núcleo de Estudos e Pesquisas da Educação na Pequena infância $(0$ a 6 anos). Estas têm como orientação a tarefa da pedagogia a quem cabe "[...] articular o conhecimento prévio e as experiências práticas na construção do conhecimento novo, garantindo voz aos sujeitos envolvidos com o problema e permitindo ao pesquisador uma posição de compartilhamento que chamaríamos de diferenciada". Portanto, é importante afirmar que o pesquisador observa a realidade (fala) de algum lugar, porém diante do compartilhamento diferenciado a subjetividade é amenizada na excelência e primazia do objeto em observação. Por outro lado, o "elemento utópico, como característica fundamental do fenômeno educativo" (CERISARA et al. (2007, p. 5), como indicado acima, desautoriza a anulação de certa subjetividade manifestada mesmo na escolha do fenômeno educativo enquanto objeto de pesquisa. Diante dos fatos só cabe interpretação persecutória da inteireza do objeto que sempre está um passo à frente. Isto é, o fenômeno educativo, por exemplo, comporta em si uma dimensão inapreensível frente a qual o pesquisador curva-se e acata os limites dos instrumentos utilizados.

Os instrumentos utilizados para descrição dos dados possibilitaram compreender como a turma e a professora coletivamente constroem as relações e como expressam as relações étnico-raciais atribuindo significado às relações sociais. Optamos pela pesquisa etnográfica porque nela,

O etnógrafo inscreve o discurso social: ele anota. Ao fazê-lo, ele o transforma de acontecimento passado, que existe apenas em seu próprio momento de ocorrência, em relato, que existe em sua inscrição que pode ser consultado novamente. (GEERTZ, 2012, p. I4).

Ainda, segundo Geertz (2012), o etnógrafo pode enfrentar alguns problemas durante o período da pesquisa, como por exemplo,

[...] uma multiplicidade de estruturas conceptuais complexas, muitas delas sobrepostas ou amarradas umas às outras, que são simultaneamente estranhas, irregulares e inexplícitas, e que ele tem que, de alguma forma, primeiro apreender e depois apresentar. (GEERTZ, p. 20).

A apropriação do estudo de caso etnográfico nos possibilitou "uma visão profunda ampla e integrada de uma unidade social". O estudo foi realizado in loco, ou seja, na instituição (ANDRÉ, 1986, p. 16).

Além das observações preliminares que serviram para aproximação/familiarização com o 
campo amenizando assim o estranhamento inicial que a tudo quer registrar, três (3) no total, realizadas no primeiro semestre de 2014, no segundo semestre, foram realizadas mais dez (10) observações na mesma turma da educação infantil totalizando assim, treze encontros. Estes treze encontros se configuram no material empírico sob o qual nos debruçaremos para as análises com foco nas ações e relações estabelecidas da e pela professora regente com as crianças.

Para a elaboração da segunda etapa, a equipe se reuniu e discutiu/elaborou a melhor forma de realizar mais coleta de dados no campo para otimizar o tempo e a disponibilidade da professora que concebeu a realização da pesquisa. Este procedimento fez-se importante para não influenciar de forma permanente no contexto educativo frente aos planejamentos da professora, nem alterar a rotina da turma. Durante as visitas foram coletados os dados, anotados em fichas de observações para elaboração do relatório e, posteriormente, as análises e confecção deste artigo.

Tabulamos os dados, fizemos consultas bibliográficas nas bases de dados científicas pertinentes ao assunto. Para Geertz, (2012, p. 14), “[...] segundo a opinião dos livros textos, praticar a etnografia é estabelecer relações, selecionar informantes, transcrever textos, levantar genealogias, mapear campos, manter um diário e assim por diante".

Percebemos durante as visitas na instituição escolar, que as crianças interagem entre si, com o corpo docente, técnico e administrativo da escola, que parecem vivenciar um ambiente harmonioso, ou seja, sem conflito aparente. Essa percepção contraria a expectativa em relação a uma escola pública localizada em área periférica tomada como um manancial de todo e qualquer tipo de violência num contínuo de pré-conceitos. Pode-se dizer que essa não violência explicita reforça a necessidade de realização de mais pesquisas que perspectivam apreender a inteireza de uma instituição escolar. Por mais que essa apreensão seja idílica ela deve permanecer no horizonte do(as) pesquisador(as). Por outro lado, essa ausência de conflito aparente não pode ser tomada como parâmetro, pois em conversas informais com a diretora da escola e com alguns docentes soubemos de algumas atitudes preconceituosas em situação de conflito velada. Assim sendo, é preciso ficar atento aos acontecimentos do interior da escola e seu entorno pois,

A criança na escola convive com a diversidade e poderá aprender com ela. Singularidades presentes nas características de cultura, de etnias, de regiões, de famílias, são de fato percebidas com mais clareza quando colocadas junto a outras. A percepção de cada um, individualmente, elabora-se com maior precisão graças ao Outro, que se coloca como 
limite e possibilidade. Limite, de quem efetivamente cada um é. Possibilidade, de vínculos, realizações de "vir-a-ser". (BRASIL, 1997, p. 123).

É no encontro com o outro que cada criança vai construindo sua identidade independente de ser negra ou não, com os pares fortalece a auto-estima, entretanto, se o contato não for agradável, se perceber atitudes de desrespeito e discriminação poderá ter problemas sérios de aceitação do próprio corpo, sentimento de inferioridade e outros. Isso se dá desde a infância. Na escola em que a pesquisa foi realizada, ouvimos relatos de que algumas mães, organizadas em grupos, não permitiam que suas crianças "brancas" se aproximassem das crianças negras. O que leva algumas mães a separarem os filhos do contato de crianças negras? Pode-se conjecturar que esse grupo de mães traz consigo concepções tomadas como estereotipadas na sociedade brasileira, pois não apresentam motivações e/ou justificativas concretas para tal proibição. Esta sugestão interpretativa deve-se às observações das diferentes formas de interação social e das ações dos atores a partir do observado no contexto educativo e no momento em que os responsáveis pelas crianças as deixam ou as buscam na instituição.

Para tentar superar o conflito existente é preciso discutir o problema e não silenciar frente a ele sendo necessário que as crianças conhecessem a história dos negros que foram escravizados, que convivam com materiais de diferentes culturas. Comungamos com a afirmação de que a educação infantil, independente do grupo social, deve ser espaço de:

[.... socialização, de convivência entre iguais e diferentes e suas formas de pertencimento, como espaços de cuidar e educar, que permita às crianças explorar o mundo, novas vivências e experiências, ter acesso a diversos materiais como livros, brinquedos, jogos, assim como momentos para o lúdico, permitindo uma inserção e uma interação com o mundo e com as pessoas presentes nessa socialização de forma ampla e formadora. (BRASIL, 2006, p. 38).

Ressaltamos que para superar atitudes preconceituosas, é preciso que os membros que compõem o ambiente escolar comprometam-se em empreender uma educação antirracista, antipreconceituosa e antidiscriminatória. A escola precisa trazer as questões de mundo externo para o contexto educativo seja possível promover programas e ações de políticas internas que possam inibir atitudes preconceituosas, discriminatórias vivenciadas nos espaços escolares. Conforme estabelece o pará- 
grafo único do Estatuto da Igualdade Social (2010, p.14).

Os programas de ação afirmativa constituir-se-ão em políticas públicas destinadas a reparar distorções e desigualdades sociais e demais práticas discriminatórias adotadas, nas esferas públicas e privada, durante o processo de formação social do país.

Além disso, as instituições devem reforçar o ensino que dispõe sobre a obrigatoriedade da inclusão, no currículo oficial das redes de ensino em todos os níveis, a história e cultura afro-brasileira, decretada pela Lei no 10.639/2003. É importante trabalhar na educação infantil leitura de livros que abordam conceitos e significados de raça, preconceito e violência de forma que as crianças aprendam as diferenças no intuito de respeitá-las.

É possível dizer que a escola não se preparou para atender as multiculturas e as diversidades, e, portanto reforça a manutenção da estrutura social, seguindo ainda a linha da homogeneidade e na formação do cidadão integrado socialmente? Se sim, é necessário que a escola abra espaço para a comunidade e atenda os sujeitos em sua pluralidade. Assim, o item seguinte orienta-se no sentido de aprofundar essa perspectiva a partir dos dados coletados.

\section{Mediações étnico-raciais a partir do contexto educativo: obser- vando o familiar ${ }^{2}$}

Diariamente as crianças, são organizadas em filas, fazem a oração universal de "Pai Nosso”. E, em seguida, a diretora agradece a presença dos pais e ou acompanhantes, passa recados às crianças/crianças sobre atividades da escola. Após essa rotina das crianças, de mãos dadas com os professores, seguem para as salas.

Foram realizadas observações em um ambiente onde tinha de 27 crianças, na sua maioria, com idade de 5 (cinco anos) e a professora regente ${ }^{3}$ que é o foco central da pesquisa. A partir da classificação racial do IBGE, pode-se dizer que as crianças pertenciam às seguintes categorias étnicas brancos, negros e pardos.

Numa percepção visual, pudemos notar, também, uma grande porcentagem de

2 Aqui fazemos uma alusão ao título de um dos vários livros, em forma de homenagem, ao eloquente antropólogo brasileiro Roberto Da Matta. 3 Formada em Pedagogia mestranda em educação, pertence ao quadro de professores efetivos leciona na instituição há uma média de 5 anos. Para proteger a sua identidade e como não obtivemos autorização para nos referirmos a ela com o seu nome verdadeiro, a partir deste momento, nos referiremos à professora com o nome fictício de Amada. 
incidência de sujeitos (negros e pardos) inseridos nessa comunidade escolar. Trabalhamos com a hipótese de que é na pequena infância que se estrutura (forja) a personalidade racista dependendo de como são elaboradas as relações sociais e pessoais nos contextos em que as crianças são e estão inseridas. Acreditamos que se as crianças, desde pequenas, não tiverem oportunidade de conviver e respeitar as diferenças, poderão, desenvolver atitudes racistas e discriminatórias, pois é na pequena infância que encontramos os vestígios daqueles que em dias vindouros apontarão o dedo indicador para classificar as pessoas com a mesma autoridade auto-incumbida com qual elegem as coisas. É importante observar a operação conceitual aqui realizada em relação a concepção anteriormente anunciada com base em Quinteiro e Carvalho (2012, p. 131). Ou seja, atitudes racistas e discriminatórias, também, são elementos da cultura passíveis de apropriação pelas crianças. Procedimento este denunciado outrora por Adorno e Horkheimer (1986).

As observações no contexto educativo, num total de dez (10) encontros com duração de 50 minutos cada, se deram numa segunda fase após iniciada a pesquisa (além da exploração do campo). Notou-se que nesta fase de observação houve modificações no fluxo dos sujeitos, ou seja, o número de crianças variou às vezes para mais e outras para menos durante as nossas observações na no contexto educativo.

Durante a verificação dos documentos institucionais pôde-se perceber que a instituição tem conhecimento da Lei 10.639/03 e da obrigatoriedade da temática "História e Cultura Afro-Brasileira e Africana" a professora trabalha com literatura africana e afro-brasileira, as quais faziam parte das aulas previamente planejadas. Esse conteúdo consta, também, na Proposta Didática do Município.

A professora regente, Amada, utiliza uma linguagem clara, firme e educada. Quando precisa chamar a atenção das crianças pede licença e em situações que é preciso usar de regras mais rígidas, faz um combinado com as crianças, como por exemplo, tirar do calendário (não conseguimos identificar a periodicidade do calendário) o dia do brinquedo por terem desrespeitado as regras, quebrando um brinquedo do colega, por exemplo. Quanto ao combinado, convém lembrar que a presença do brinquedo, jogos, brincadeiras e lúdico na educação infantil, estes elementos deveriam fazer parte da rotina diária das crianças, pois é por meio deles que as crianças, especialmente, aprendem.

Percebem-se alguns momentos de conflito na turma do pré-II. Apesar da calmaria pôde-se observar que as crianças brigam, se jogam ao chão, batem uns nos outros, quebram as regras de con- 
vivência pré-estabelecidas junto a professora, fazem brincadeiras em relação às etnias, não querem ser amigos, falam alto, xingam em voz alta, conversam, pegam brinquedo dos colegas etc., diante da tentativa frustrada do adulto (professora) que pede silêncio e tenta em vão co-ordenar o contexto educativo. Instala-se, portanto, um conflito geracional, pois o que aparentemente os adultos se propõem a ordenar submete-se à ordem das crianças, atores, principais deste contexto. Pode-se dizer que, no contexto da educação infantil, onde há frustração do ponto de vista do controle (falta de autoridade), instaura-se o autoritarismo protagonizado pelos adultos que, neste caso, se propõem a conter e orientar na permanente formatação das crianças. Adjetivar esta outra ordem é próprio dos que ainda reivindicam um poder reticente a questionamentos no contexto da educação infantil. Não advogamos pela falta de referencialidade ou apresentação do mundo às crianças pelos adultos, mas sim por uma interação equânime que privilegie o protagonismo das crianças na perspectiva do estabelecimento de outra ordem diferente da já pensada e estabelecida pelos adultos nos contextos educativos, ou seja, diferente da ordem adultocêntrica. Ao observarmos esse tipo de atitude instalase um paradoxo no contexto educativo, qual seja, como a professora consegue manter uma postura firme e dócil diante do comportamento turbulento das crianças? Este paradoxo é reforçado pela aparência calma e sossegada da turma. Em outras palavras, existe um padrão calmo costumeiro de ação nas relações no contexto educativo entre os sujeitos envolvidos que abalados momentaneamente por conduta turbulenta.

As crianças não deixam de socializar-se, quando brigam entre si, batem nos amigos, se jogam ao chão, falam em voz alta, ou dizem que um não quer mais ser amigo/a do/a outro/a. São questões próprias de convivência no contexto educativo que instauram outras instâncias de socialização, não apenas as apaziguadoras. Essa realidade pode reforçar a percepção da turbulência por se tratar de procedimentos momentâneos. Isso é verificado, também, com relação ao descumprimento dos combinados por parte das crianças junto à professora. Assim, quando deixam de cumpri-los como dissemos acima permitem a ação repressora da professora flutuante entre autoridade e autoritarismo, como se pode observar nessa passagem:

A professora é comunicada por uma criança que relata que um colega pegou um brinquedo que estava sobre a mesa e guardou-o na mochila. Em nenhum momento ela acusou a criança de ter pegado o brinquedo, apenas chamou a criança para uma conversa franca, mas o menino respondeu agressivamente falando alto, se jogando ao chão, chorando e dizendo que não havia pegado o brinquedo. Não obtendo resultado, pede para chamar a direção, diante da atitude da professora o brinquedo aparece. (Diário de Campo, 2014). 
Uma hipótese é de que para a professora esse tema pode não ser apropriado para trabalhar com crianças nessa faixa etária e quiçá não faça parte do currículo escolar, entretanto, não podemos esquecer que as crianças são curiosas e estão em fase de explorar o mundo que as cerca.

Outro momento no qual foi possível perceber ausência da autoridade (ação da professora) que deflagra, assim como na passagem anterior, a fragilidade em lidar com questões multidisciplinares foi a não intervenção na interação de uma menina negra com as demais crianças. Para não camuflar as situações de tensão social nos referiremos à criança que sofreu a ação discriminatória de outras crianças como menina negra para localizar a intencionalidade de quem discrimina, ou seja, elegemos a quem empreenderemos nossa ação discriminatória. Pode-se dizer que o pertencimento étnico da criança motivou a ação discriminatória, pois não se identificou, no contexto educativo, outra ação e situação semelhante diante de outras crianças com radical étnico diferente. Por isso dar um nome fictício para a menina negra, já que não podemos identificá-la com o nome verdadeiro, camuflaria a identidade e pertencimento étnico de quem sofre discriminação e preconceito num continuo quase que mitológico (que se baseia num passado; na permanência do presente e na continuidade do futuro) de infringirmos limites à liberdade alheia. É sabido que o racismo tem cor em nosso país. A menina negra, como constatamos nas observações, apresenta pouco desempenho, pouca participação nas atividades pedagógicas e sente muito sono (ela cochilava constantemente e as colegas, crianças, sempre riam dela). Segundo relato da professora, a menina negra está sempre quieta e calada e isola-se deixando de interagir com os amigos. A falta de interação com os pares é um fator preocupante porque "É com o outro, pelos gestos, pelas palavras, pelos toques e olhares que a criança construirá sua identidade e será capaz de reapresentar o mundo que a cerca”. (BRASIL, 2006, p.31).

Assim, todas as atitudes das crianças devem ser analisadas bem como o contexto educativo, a decoração, os materiais didáticos, os livros e suas ilustrações, os contos e outros. Todos esses recursos auxiliam na compreensão do outro e do mundo. Por ora isso serve apenas como indicação a ser desenvolvida em outros trabalhos futuros com mais fôlego.

Em um dos encontros pudemos perceber, quando desenvolvia atividade de desenho, uma das colegas da menina negra caçoou do desenho dela deixando-a chateada. Neste momento, a pro- 
fessora interviu, sem insistência, buscando diálogo com a menina negra, mas sem obter sucesso. Certamente a menina negra já percebeu que não é bem aceita pelo seu grupo de amigos, e talvez por isso não se mostre confiante para realizar as atividades no contexto educativo, para se expressar. É preciso:

Compreender que aquele que é alvo da discriminação sofre de fato, e profundamente, é condição para que o professor, em no contexto educativo, possa escutar até mesmo o que não foi dito. O professor precisa saber que a dor do grito silenciado é mais forte do que a dor pronunciada. (BRASIL, 1997, p. 139).

Claro está que as nossas observações no contexto educativo não pretendem trazer a tona as questões étnico-raciais na sua inteireza e sim uma dimensão das mesmas de acordo com as nossas percepções. É preciso um olhar atento a cada movimento dos sujeitos, pois numa fala, numa brincadeira ou num gesto podem estar implícitas essas questões que podem passar despercebidas, mas não a um olhar atento para uma análise detalhada dos fatos.

\section{Algumas considerações}

Por se tratar de uma pesquisa em curso, neste artigo buscamos traçar as linhas norteadoras da questão central do estudo, qual seja, apresentar, compreender e analisar a relação que a professora estabelece junto às crianças. Uma das cenas aqui analisadas indica o germe de uma personalidade que dispensa quantificações da sua ocorrência diante dos danos irreparáveis que pode causar em suas vítimas. Portanto, não é a recorrência da ação que identifica uma personalidade racista e sim a possibilidade da manifestação tal personalidade. Por isso que é na infância que se deve agir contra tais condutas.

Portanto, iniciamos o artigo com uma apresentação geral do contexto da pesquisa e do conceito que estrutura a nossa hipótese. A apresentação do percurso metodológico nos ajudou a orientar o leitor dos caminhos e escolhas que tomamos para perscrutar o nosso objeto como dissemos anteriormente. Assim, nas mediações étnico-raciais, contextualizamos as relações que a professora estabelece junto às crianças do pré-II focando, na última parte, a relação com menina negra, a única criança negra deste contexto educativo a fim de afunilar as relações étnico-raciais do ponto de vista inter-étnico. Compreendemos que as relações étnico-raciais extrapolam o binômio Branco/Negro. 
Portanto, a relação com menina negra deve ser tomada enquanto força do exemplo que pode sim refletir as relações estabelecidas em contextos mais abrangentes. Cabe aos adultos que interagem com as crianças nos diversos contextos educativos se perguntarem quanto a validade deste caso como exemplar. Será que nunca presenciaram situações parecidas? É uma pergunta que este artigo, na melhor das hipóteses, pretende trazer à consciência daqueles que se dedicam ao contexto educativo.

A relação, indicada acima entre a professora e menina negra, por sua vez, não era o foco central da pesquisa, porém a sua eloquência torna tangível a atenção que a ela dedicamos. Portanto, a relação da professora deste contexto educativo deflagra a ambiguidade da ação ou ato de educar, qual seja, reter e orientar (formar). Esse contexto, também, indica o germe da personalidade racista por meio das chacotas das crianças em relação à menina negra e da falta de uma intervenção mais efetiva por parte da professora diante de tal fato. Portanto, isso reforça a necessidade de aprofundarmos, do ponto de vista longitudinal e teórico, a pesquisa.

O contexto da educação é composto, em alguma medida, pela dupla ação de (1) reter e (2) orientar. A primeira se manifestou no contexto educativo estudado ao impor sanções às crianças quando descumprem o previamente combinado e transfere o poder de resolver o conflito para terceiros; já a segunda demarcou-se no planejamento de todas as atividades que acontecem no contexto educativo, ou seja, há um planejamento prévio daquilo que irá ocorrer no decorrer do dia no contexto educativo sob a tutela da professora regente.

A pesquisa também possibilitou perceber a necessidade de fortalecimento da identidade e autoestima da criança negra. Outras pesquisas demonstram que a população negra é a que mais fracassa na escola, portanto, devemos repensar como tem sido o cotidiano dessas crianças nos contextos educativos, ou seja, a sensibilidade e o diálogo devem permear as práticas pedagógicas. Na sua macro história o Brasil registra inúmeras desigualdades que resultam em discriminações, especialmente contra negros e indígenas, impedindo, desta forma, seu pleno desenvolvimento econômico, político e social. Essa discriminação segundo Fúlvia Rosemberg (2013) impõem uma dinâmica de segregação social para as populações negras ao internalizarem os mecanismos de dominação infligidas pelas camadas sociais mais abastadas e pela elite branca. 


\section{Referências}

AGOSTINHO, Kátia Adair. O Espaço da Creche: Que lugar é este? Dissertação (Mestrado). Universidade Federal de Santa Catarina, Centro de Ciências da Educação, 2003. Disponível em: http://www.ced.ufsc.br/ nee0a6/katia.pdf. Acesso em: 10/07/2013.

ANDRÉ, M. E .D. A de. Etnografia da Prática Escolar. 12. ed. Ed. Campinas, São Paulo: Papirus, 1986.

.Pesquisa em educaçáo: abordagens qualitativas. São Paulo, SP: EPU, 1986.

AGUIAR. P. L. PCNs No Contexto da Educação Infantil: Relações Possíveis entre o Papel do Professor, Currículo e Brincadeira. Universidade Federal do Rio Grande do Sul/UFRS, Três Cachoeiras-RS, 2010.

BRASIL. Parâmetros Curriculares Nacionais: pluralidade cultural, orientação sexual. Brasília: MEC/SEF, 1997.

BRASIL. Orientaçóes e Açóes para a Educação das Relações Étnico-Raciais. Ministério da Educação e Cultura/ Secretaria da educação Continuada, Alfabetização e Diversidade Brasília: MEC/SECAD, 2006.

BRASIL. Diretrizes Curriculares Nacionais para a Educaçáo das Relaçóes Étnico-Raciais e para o Ensino de História e Cultura Afro-Brasileira e Africana. (DOU no 8, 10/1/2002, Seção 1, p. 1), Brasília, 9 de janeiro de 2003.

Lei no 10.639, de 9 de janeiro de 2003. Diário Oficial [da] República Federativa do Brasil, Brasília, DF, 09 janeiro 2003. Disponível em: <http:// www.planalto.gov.br/ccivil/ LEIS/2003/L10. 639. htm>. Acesso 21 jun. 2014.

MEC/CNE. Resoluçáo CP/CNE no 1, de 17 de julho de 2004. Institui as diretrizes curriculares nacionais para a Educação das Relaçôes Étnico-Raciais e para o ensino da História e Cultura Afro-Brasileira e Africana. Diário Oficial da União, Poder Legislativo, Brasília, DF, 22 jun. 2004.

Referencial Curricular Nacional para a Educaçáo Infantil. Ministério da Educação e do Desporto. Secretaria de Educação Fundamental - Brasília: MEC/SEF, 1998.

GEERTZ. C, 1926 A intepretaçáo das culturas. Rio de Janeiro: LTC, 2012.

HALL, Stuart. A identidade cultural na pós-modernidade. 11. ed. Tradução Tomaz Tadeu da Silva e Guacira Lopes Louro. Rio de Janeiro: DP\&A Editora.

MWEWA, C. Muleka e OLIVEIRA, Patrícia da Costa. Desafios ao protagonismo feminino para a geração de renda em Laguna-SC: gênero, bolsa família e serviço social. Poiésis - Revista do Programa de Pós- Graduaçáo em Educação, v. 7, n. 11, Jan/Jun 2013. P. 168 - 181.

NUNES, César; SILVA, Edna. A educaçáo sexual da criança. Campinas: Autores Associados, 2000.

ROCHA, Eloisa Acires Candal; CERISARA, Ana Beatriz; SILVA FILHO, João Josué da. Educaçáo infantil: uma trajetória de pesquisa e indicaçóes para a avaliação de contextos educativos.. Zero-a-Seis, Florianópolis, v. 9, n. 15, p. 1-25, abr. 2008. ISSN 1980-4512. Disponível em: <https:// periodicos.ufsc.br/index.php/zeroseis/article/view/875/808 $>$. Acesso em: 30 set. 2015. doi:http:// dx.doi.org/10.5007/875. 
ROCHA, Eloísa A. C. OSTETTO, Luciana Esmeralda. O estágio na formação universitária de professores de Educação Infantil. In: SEARA, Izabel Christine et al. (Orgs.). Práticas pedagógicas e estágios: diálogos com a cultura escolar. Florianópolis: Letras Contemporâneas, 2008, p. 103-116.

ROCHA, Eloisa Acires Candal e KRAMER, Sônia. Educação Infantil: enfoque em diálogo. Campinas: Papirus. 2011.

ROSEMBERG, F. 0 a 6: desencontro de estatística e atendimento. Cadernos de pesquisa. São Paulo, fundação Carlos Chagas, 1986.2v.

Raça e educação inicial. Cadernos de pesquisa, São Paulo (77): 25-34, maio, 1991.

ROSEMBERG, L. Educaçáo e desigualdade social: rendimento escolar de alunos de diferentes origens sociais. São Paulo, 1981. Dissertação (mestrado) PUC-SP.

ROSEMBERG, Fulvia. Educação infantil e relaçóes raciais: a tensão entre igualdade e diversidade. São Paulo: Cad. Pesqui. vol.44 nº153, 2014.

Relaçóes raciais e rendimento escolar. Disponivel em: $<$ http://www.fcc.org.br/pesquisa/publicacoes/cp/arquivos/787.pdf $>$. Acesso em 12 de junho de 2015.

QUINTEIRO, J. ; CARVALHO, D. C. . Infância, escola e formação de professores: relaçôes e práticas pedagógicas em debate. In: Beleni Salete Grando; Diana Carvalho de Carvalho; Tatiane Lebre Dias. (Org.). Crianças - infâncias, culturas e práticas educativas. 1ed.Cuiabá - MT: Editora da UFMT, 2012, v. 1, p. 125-148. 